\title{
Influence of Network Structure on Schedule Performance - Extending Criticality Index to Capture Ripple Effect of Delays
}

\author{
Gunnar Lucko $^{\mathrm{a} *}$, Yi Su ${ }^{\mathrm{a}}$, Richard C. Thompson, Jr. ${ }^{\mathrm{a}}$ \\ ${ }^{a}$ Department of Civil Engineering, Catholic University of America, 620 Michigan Avenue NE, Washington, DC 20064, USA
}

\begin{abstract}
Many construction projects suffer delays. This situation is exacerbated in larger projects with their more complex schedules, because of a 'ripple effect' - the phenomenon that relatively small delays of activities may not just locally affect direct successors in a network schedule, but spread, accumulate, and globally impact its project finish date negatively. This research therefore studies the occurrence and behavior of said ripple effect by examining dependency structures of network schedules systematically. Its contribution to the body of knowledge is threefold: First, it develops a methodology that multiplies the elements from the correlation coefficient matrix with the reachability matrix to measure said ripple effect. It plots the cumulative product matrix in three dimensions to visualize the relative potential ripple effect of individual activities. Second, it conducts a sensitivity analysis by experimenting with schedule structures that range in complexity from sequential to parallel. A constant relation is found that the sum of the product of elements in the noncumulative productive matrix and its corresponding criticality index always equals one. Cruciality is defined. Third, it substantiates its results by simulating a benchmark schedule and derives practical suggestions for delay avoidance and delay analysis that considers how the network structure determines the behavior of a schedule.
\end{abstract}

(C) 2018 The Authors. Published by Diamond Congress Ltd., Budapest University of Technology and Economics Peer-review under responsibility of the scientific committee of the Creative Construction Conference 2018.

Keywords: Beta; delay analysis; ripple effect; schedule performance; simulation.

\section{Introduction}

'How is my project doing?' is a question that is constantly on project managers' minds. This question touches upon fundamental dimensions of project planning and control, namely the conceptual 'iron triangle' of time, cost, and scope, to which quality and safety are often added [1]. Quality of work products is routinely established [2] by many state and Federal government agencies by establishing performance (e.g. compressive strength of concrete) or prescriptive specifications (e.g. on-center distance of roof rafters), or by specifying certain manufacturers and models of installations or acceptable equivalents. It is trackable by number of defects or rework [3]. Safety is closely related and can be measured equally well via the recordable injuries and fatalities per the Occupational Safety and Health Administration regulations [ibid.] and is strongly financially incentivized via the Experience Modification Rate [4], a three-year running average of actual versus expected claims, which gives an intuitive and unitless percentage value.

But measuring performance of non-physical aspects is surprisingly challenging. The Earned Value Management divides said question into being 'on schedule' and 'within budget'. Accordingly it compares planned and actual time and cost values at the resource-level or activity-level within construction projects. It casts performance into absolute and relative terms as time and cost variances and time and cost performance indices, respectively [5]. But this creates some odd and counterintuitive problems [6, p. 18]: "A major problem with the schedule performance index is that it will always be in unity when the project is completed, regardless of whether the project is ahead, on-time, or behind 
schedule." Just because a project is finished, its performance has a value of one and the performance appears to have been perfect, even if in reality it may have been massively delayed. "Another problem with the schedule indicator is that the $S V$ [schedule variance] is measured in monetary units, which makes it difficult to understand" [ibid., p. 18].

A recent study repaired these two problems by adding an 'earned schedule' in time units [7]. It was determined in a cost-over-time coordinate system by reading a Planned Value on the planned progress curve for the current time, moving horizontally until intersecting the same Earned Value on the actual progress curve, and moving downward to read Earned Schedule on the time axis. If it was less than the current time, the project was behind schedule. Related studies surveyed by [5] created the conceptually identical Earned Duration. But fundamental problems remain: First, its forecasting ability is limited to extrapolating the current trajectory within a project [8]. Second, it ignores previous performance of a particular subcontractor, which - if evaluated in a statistical manner - could give valuable insights. Third, it precludes extrapolating beyond completed known projects to forecast the expected performance of future projects. Fourth, its approach does not offer scalability to compare performance at various levels of detail that range from activities (or even tasks) via stages and phases to entire projects, portfolios or programs of multiple projects by companies or agencies, and industry sectors. And fifth, it completely ignores the structure of the network schedule with which most construction projects are planned and controlled, which is significant for how delays may impact a project. The former items are currently being explored under related research [9]; the latter is the topic of this paper.

\section{Literature Review}

Performance in construction project scheduling means the ability of the productive resources to set and meet their target dates, in other words, to plan and control at an appropriate levels of detail. Extracting and ranking potentially causal or risk factors for delays from project data [10,11], synthesizing them [12, 13, 14], or - conversely - critical success factors $[15,16]$ received much scientific attention. Moreover, many studies documented the phenomenon of pervasive delays across various types of projects [17, 18, 19] and in different countries [20,21, 22]. Furthermore, a host of delay analysis methods were developed [23, 24, 25, 26], all of which had limitations and exhibited larger or smaller biases toward owner or contractor [27]. This impacts whether they are considered excusable, compensable, both, or not $[28,29]$. But a major gap exists in the literature with respect to understanding how delays themselves occur and propagate within schedules: For network schedules, several potentially influential factors have remained largely ignored, notably [30, pp. 510-511] "the analysis and classification of the shape or morphology of each project network; the automatic production of easily readable graphic representations of the network to have a visual image of the network's morphology; [and] the relationship between the morphology and the uncertainty concerning the total duration of the project." To describe schedule network structure quantitatively, complexity indices were explored and defined by various scholars. Nassar and Hegab [31] developed a complexity measure based on the connectivity between activities without considering redundant links. Nassar [32] also evaluated the correlation between network complexity and project complexity. Sinha et al. [33] developed a metric for project complexity from the project manager's view, which considered complexity-generating factors of skill and experience of workers. Vidal et al. [34] (echoed by Sheard [35]) advocated that project performance depends on project complexity, which ideally should be managed not by minimizing it, but maintaining it within an optimum range. Latva-Koivisto [36] identified criteria for a good complexity measure by comparing alternative measures from graph-theory literature of mathematics.

\subsection{Performance Measurement}

Numerous scholars have conducted research on project performance measurement. Haponava and Al-Jibouri [37] developed a process-based key performance indices system to evaluate projects' performance when they are still in process. Nassar and AbouRizk [38] expanded performance measurement to an integrated system that considered critical objectives and transferred them into a single performance index by assessing priority weights for them. Esmaeili et al. [39] reviewed independent variables that led to project success on various completed projects. Sarhan and Fox [40] and Lyer and Jha [41] summarized critical factors that affect project performance in Great Britain and India, respectively. Tavares et al. [30] explored the relation between project delay and the morphology of its network. They defined six indicators per Table 1 to describe the morphology, generated randomized networks, calculated the indices, and determined their relationship with the total project duration. They included defining indices for activity count, relative longest path length, network width in each sequence step (termed 'progressive level'), and relative link density. But this study interpreted (non-redundant) links in network schedules to have a length akin to distance and its understanding of morphology remained limited to an overall enveloping 'shape' of serial versus parallel, i.e. 
sequential versus concurrent networks. Its indices $I_{1}-I_{6}$ only measured global network topologies, while the total duration distribution and its mean and standard deviation were also at the global level. But at the local (activity) level they only stated confusingly that "for each activity, $i$, the mean $\mu_{\mathrm{i}}$ is generated using an uniform generator, $a_{i}$, within $[a-\Delta, a+\Delta]$ and scaled in order that the total duration, TD, of the critical path, $\mathrm{CP}$, assuming that the duration of each activity, $i$, will be equal to its mean, $\mu_{i}$, will be made equal to 1000" [ibid., p. 520]. In simpler words, its very limited approach did not consider how variations in the duration of individual activity affect total project duration, it did not experiment with behavior of different structures, and no comparison to other complexity indices was offered.

Table 1. Six morphology indicators of a project network (Adapted from Tavares et al. 1999)

\begin{tabular}{|c|c|c|}
\hline Perspective & Index & Formula \\
\hline \multirow{5}{*}{ (A) Graphical shape } & $I_{1}$ & Size equal to activity count \\
\hline & $I_{2}$ & $\begin{array}{l}I_{2}=(M-1) /(N-1) \quad \text { Relative length: How serial is shape } \\
\text { Where length } M=\max _{i \in \Omega} a_{i} \text { and } 0 \text { (parallel) } \leq I_{2} \leq 1 \text { (serial) }\end{array}$ \\
\hline & \multirow{3}{*}{$I_{3}$} & Only meaningful if $N>M$ \\
\hline & & $\sum_{a=1} I_{3}(a)=1$ \\
\hline & & Width: Activity count per progressive level \\
\hline \multirow{2}{*}{ (B) Count of non-redundant direct precedence links $D$} & \multirow{2}{*}{$I_{4}$} & $I_{4}=n(1)-N /(D-N)$ Relative link density with length equaling 1 \\
\hline & & Where $0 \leq I_{4} \leq 1$, because $n(1) \leq D$ \\
\hline \multirow{2}{*}{ (C) Length $L$ of non-redundant direct precedence links } & & $0 \leq I_{5}=p \leq 1$, where $0 \leq p \leq 1$ \\
\hline & & $0 \leq I_{6}=(V-1) /(M-1)$, where $V$ is maximal length $\leq M-1$ \\
\hline
\end{tabular}

\subsection{Beta Index and Correlation Coefficient}

To assess how variations of individual activities affect the project schedule performance, the authors are inspired by measuring financial performance from which they have developed a macro-level index (across multiple projects), whereas the correlation coefficient that will be used in this paper resides at the micro-level (within a single project).

In finance, beta is a volatility measure that describes the sensitivity of the returns of a stock relative to its market [42]. Per Equation 1, beta is the ratio of covariance between stock return and market return to the variance of market return. It is similar to (but not the same as) the formula of correlation coefficient of Equation 2, which divides the covariance of stock return and market return by the product of their standard deviations [43]. Note that beta does not have boundaries like the correlation coefficient. The latter is between -1 and 1 , where -1 means that stock and market move opposite to each other, 0 means that they have no relationship, and 1 means that a stock moves with its market. But beta values could exceed this range [44, 45]. They are mathematically related by Equation 3, where beta equals the correlation coefficient multiplied by the standard deviation of the stock divided by the standard deviation of the market. Having successfully adopted the beta concept to measure scheduling performance under prior research [9], a summary is provided here: Suppose one subcontractor participates in multiple projects (market), then the volatility of its schedule performance relative to those projects is measured per Equation 4. Note that the schedule performance beta must be calculated across multiple different projects, just like there are unique daily values of the stock market. It is obtained by dividing the covariance between a subcontractor's performance in different projects and the projects' (market's) performance by the variance of the projects' performance [46]. Performance here refers to time difference of planned minus actual activity duration or project duration, respectively. But schedule performance of an individual activity relative to its successor or even to the entire project still remains to be explored within this paper.

$$
\begin{aligned}
& \beta_{i}=\frac{\operatorname{Cov}\left(\tilde{r}_{i}, \tilde{r}_{m}\right)}{\operatorname{Var}\left(\tilde{r}_{m}\right)} \\
& \rho_{i, m}=\frac{\operatorname{Cov}\left(\tilde{r}_{i}, \tilde{r}_{m}\right)}{\sigma_{\widetilde{r}_{i}} \cdot \sigma_{\widetilde{r}_{m}}} \\
& \beta_{i}=\rho_{i, m} \cdot \frac{\sigma_{\widetilde{r}_{i}}}{\sigma_{\widetilde{r}_{m}}}
\end{aligned}
$$




$$
\beta_{i}=\frac{\operatorname{Cov}\left(\tilde{d}_{i}, \tilde{d}_{\text {Total }}\right)}{\operatorname{Var}\left(\tilde{d}_{\text {Total }}\right)}
$$

Table 2 compares existing methods that have sought to study the relation between the structure of a schedule and the risk of delay. But Tavares et al. [30] did not analyze how local activity duration influences total project duration. In their method, network structure and the mean of an individual activity duration were independent variables with respect to the effect on the total project. It is important to note that using the mean value of activity duration misses much useful information instead of using its random durations, as "criticality constellations by whether an activity duration increase (i.e. delay) or decrease (i.e. acceleration) will cause the project duration to increase, decrease, or not be impacted" [47]. Different from those methods, this paper explores the relation between the structure of a schedule as captured through an appropriate proven complexity index and the risk of it being delayed. Whereas beta had measured and aggregated an individual subcontractor's performance across numerous projects compared to the totality of these projects [9], this research determines the correlation coefficient between activity finish times within a schedule. The expected sign $(+, 0,-)$ of this correlation coefficient completely matches with the behavior of an activity within the aforementioned criticality constellations. Note that this study is not limited to examining critical activities (which would be identified initially via a static analysis), but also applies to non-critical activities. Toward the overall goal of understanding the effects of local delays within a network, three Research Objectives are set:

1. Create a method to measure the correlation between activity finish times and their underlying schedule structure;

2. Explore the possibility of incurring ripple effects by systematically examining the structure of network schedules;

3. Simulate and study a benchmark schedule to derive practical suggestions for delay avoidance and delay analysis.

Table 2. Comparison of global and local schedule performance methods

\begin{tabular}{llcl}
\hline Method & \multicolumn{2}{c}{ Independent variable(s) } & Dependent variable(s) \\
\cline { 2 - 4 } & Network indices & Individual activity effect & Total project effect \\
\hline Tavares et al. [30] & Morphology $\mathrm{I}_{1}$ to $\mathrm{I}_{6}$ & Activity duration (mean value) & Total duration, $\mu, \delta, Q_{0.05}, Q_{0.95}$ \\
Beta by Thompson et al. [35] & Restrictiveness estimator (RT) & \multicolumn{2}{c}{ Beta (based on duration) } \\
Method of this paper & Reachability matrix & \multirow{2}{*}{ Correlation coefficient matrix (based on finish time) } \\
\hline
\end{tabular}

\section{Methodology}

\subsection{Algorithm Development}

Taking the correlation coefficient index, which is similar to beta but can be used within a schedule (not between multiple ones), this paper explores the ripple effect that is caused by network structure. It does so by analyzing two matrices; the reachability matrix for capturing the entire relevant information about the network structure, and the correlation coefficient matrix (based on activity finish time) for measuring the ripple effect within a schedule. Figure 1 shows the flowchart of the methodology, which has three modules; the critical path method (CPM) module, the schedule structure module, and the output visualization module. First the CPM module collects the basic schedule input data including activity names, relations and their type (finish-to-start (FTS), start-to-start (STS), finish-to-finish (FTF), or start-to-finish (STF)), and probability distribution (e.g. Normal, Beta, Exponential, Triangular, Uniform, etc.) for each activity duration. Then a Monte Carlo simulation runs many repetitions (e.g. 1000) to generate datasets of randomized durations for all activities to allow examining their behavior statistically. Using the static critical path method (CPM), the earliest finish (EF) of each activity is calculated for each recorded simulation run. The last step in this module is creating the correlation coefficient matrix for said finishes. A correlation coefficient between any two different activities is calculated per Equation 5, no matter whether they are actually connected within the network. As this correlation coefficient matrix is symmetric around its descending diagonal [48], for brevity only upper triangular elements are listed in the remainder of this paper. Its element $\rho_{i j}$ is the correlation coefficient of activities $i$ and $j$.

$$
\rho_{E F_{i}, E F_{\mathrm{j}}}=\frac{\operatorname{cov}\left(E F_{i}, E F_{j}\right)}{\sigma_{E F_{i}} \sigma_{E F_{j}}}
$$


Due to the fact that correlation does not imply causation, element values do not mean that causative relations exist between those activities. But within a schedule, a sequential relationship clearly implies causality from predecessors to successors. Therefore the schedule structure module calculates the reachability matrix to capture the more narrow causative relations within a schedule. The reachability matrix $\left(R=\left[r_{i j}\right]_{n \times n}\right.$ is an $n$ by $n$ matrix, where $n$ is the number of activities and $r_{i j}=1$ if activity $i$ and $j$ are reachable (connected via a directional path), else $r_{i j}=0$ [49]. Of course, an activity on node (AON) network graph could be generated using the reachability information in this module [50].

Taking the element-by-element product of both matrices yields information on the correlation coefficient between two researchable activities within a schedule: Element $\rho_{i j} \cdot r_{i j}$ in the product matrix is the correlation coefficient of activities $i$ and $j$ if (and only if) they are directly reachable, else $\rho_{i j} \cdot r_{i j}=0$. Finally the output visualization module displays two pieces of information: A 3D profile is plotted whose two axis dimensions are activity names (same as in the product matrix), while the third dimension is the correlation coefficient between said pair of connected activities. A ripple effect may be seen in this 3D figure. Second, the crucial path(s) and activities can be highlighted to retrace the causes of a potential ripple effect. This new approach as organized in Figure 1 fulfills Research Objective 1.

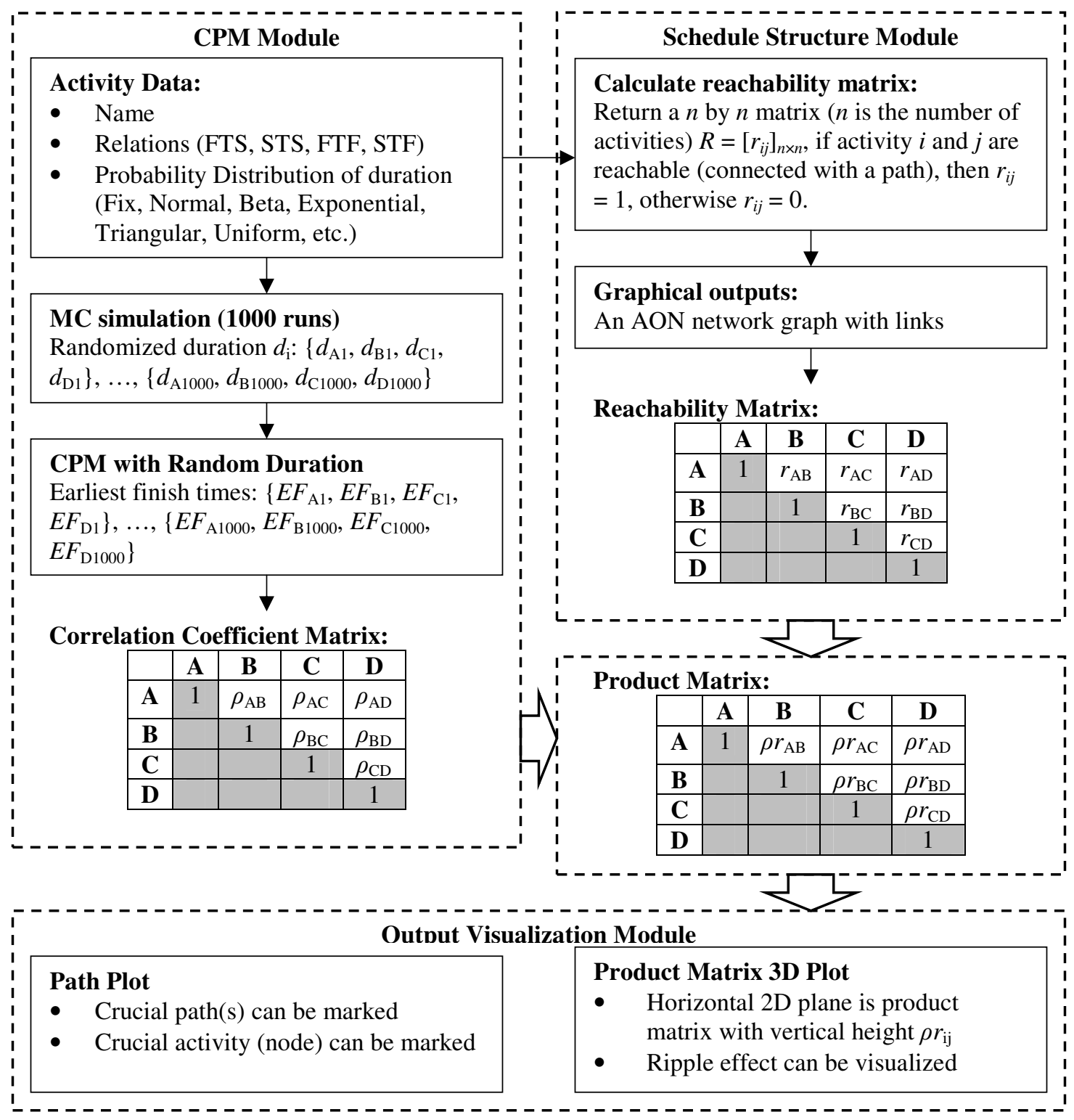

Figure 1: Methodology Flowchart 


\subsection{Simulation Experiments}

To explore the mathematical behavior of the product matrix, test schedules with six activities that are linked in various ways are used for experimentation. These six activities receive different probability density functions (PDF) as Figure 2 shows. Figure 3a shows the simplest dependency - purely sequential - with a dummy source and sink (schedule \#1), where critical activities $(\mathrm{CI} \neq 0)$ are plotted with thick frame and crucial activities (newly defined as CI $\left.\cdot \Delta \rho_{i j} \geqslant 0.1\right)$ are plotted in gray. Since element $\rho_{i j} \cdot r_{i j}$ in the product matrix gives the correlation coefficient of two connected activities $i$ and $j$, this value inherits all correlation coefficients between activity $i$ and its predecessors, plus its own correlation. Thus correlation coefficient $\rho_{i j}$ is the cumulative correlation coefficient of all predecessors of $i$ plus its own correlation coefficient per Equation 6. Note that the correlation coefficient values in the last matrix column increase. Hence the dark square in the 3D profile of the product matrix in Figure $3 \mathrm{~b}$ grows from activity 1 to 6; this cumulative growth is the ripple effect. Equation 7 gives the noncumulative correlation coefficient $\Delta \rho_{i j}$ between two reachable activities' finish time. Figure $3 \mathrm{~b}$ shows these correlation coefficients of individual activities without this inherited ripple effect. The sum of all activities' noncumulative correlation coefficients equals one, which is intuitively correct for sequential schedules and allows deriving Equation 8: The sum of all noncumulative correlation coefficient values multiplied by their criticality indices (CI) must equal one. Equation 8 has two cases; $\mathrm{CI}=1$ versus a fractional $1>\mathrm{CI}>0$, because for $\mathrm{CI}=1$ activities, the count of runs where $\mathrm{CI} \neq 0$ is equal to the total simulation runs $n$. But for $1>\mathrm{CI}>0$ activities, $n_{\mathrm{i}}$ is the count of activity $i$ being critical among $n$ runs. Thus in the fractional case, before summation each noncumulative correlation coefficient $\Delta \rho_{i j}$ is first multiplied by $n_{\mathrm{i}} / n$, which is $\mathrm{CI}_{i}$ itself.

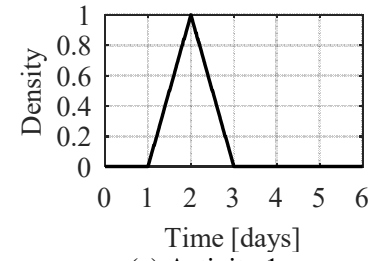

(a) Activity 1

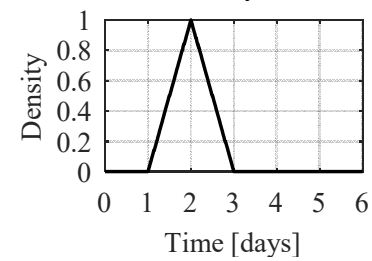

(d) Activity 4

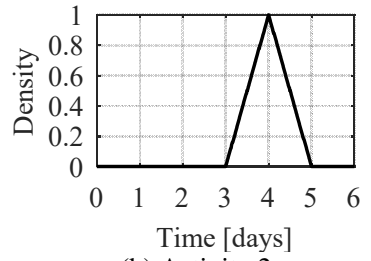

(b) Activity 2

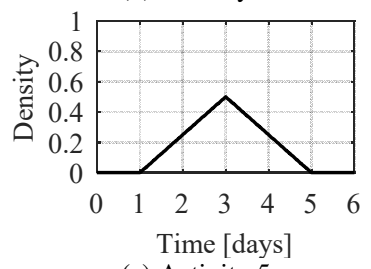

(e) Activity 5

Figure. 2. PDF Profiles for Six Activities

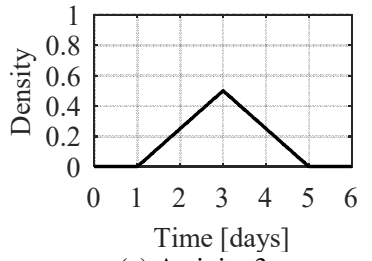

(c) Activity 3

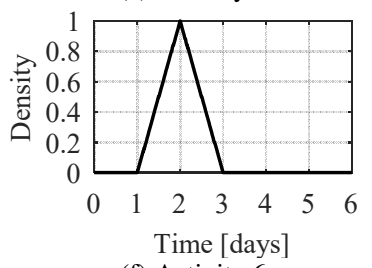

(f) Activity 6

$$
\left[\rho_{E F_{i}, E F_{j}}\right]_{6 \times 6}=\left[\begin{array}{llllll}
1 & 0.686 & 0.393 & 0.347 & 0.249 & 0.262 \\
0 & 1 & 0.533 & 0.414 & 0.326 & 0.362 \\
0 & 0 & 1 & 0.906 & 0.692 & 0.687 \\
0 & 0 & 0 & 1 & 0.791 & 0.761 \\
0 & 0 & 0 & 0 & 1 & 0.962 \\
0 & 0 & 0 & 0 & 0 & 1
\end{array}\right]
$$

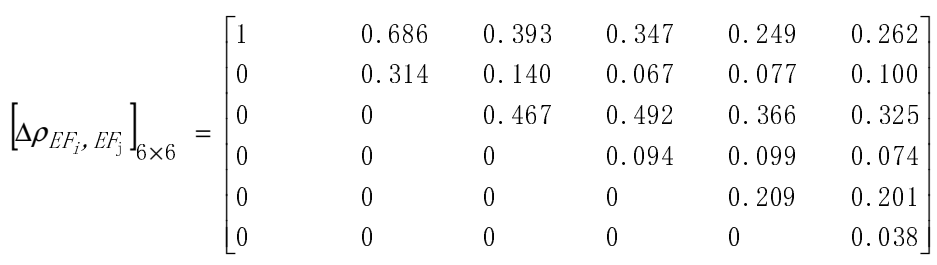

$$
\sum_{i=1}^{n}\left(\Delta \rho_{E F_{i}, E F_{j}} \cdot C I_{i j}\right)=1
$$




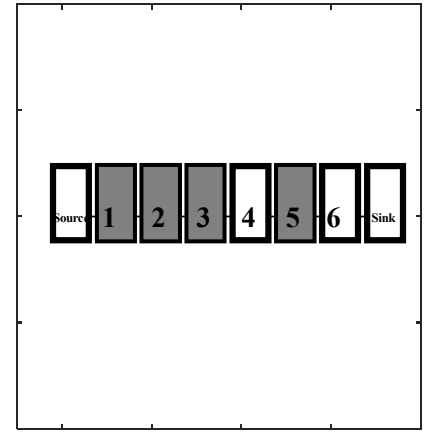

(a) Network Graph (Schedule \#1)

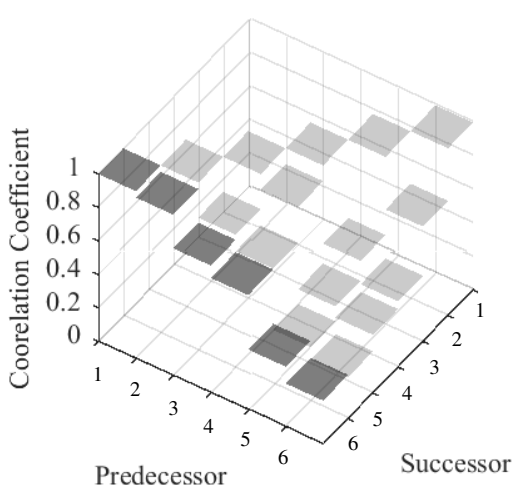

(b) Cumulative Product Matrix Profile

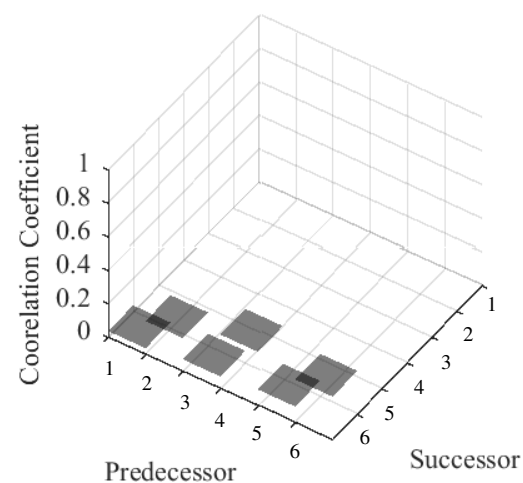

(c) Noncumulative Product Matrix Profile

Figure. 3. Correlation Coefficient Profiles for Schedule \#1

To verify Equation 8, noncumulative correlation coefficients $\Delta \rho_{i j}$ are calculated for the networks of Figures $4 \mathrm{a}-4 \mathrm{c}$ (schedules \#2-\#4) and listed as Table 3 columns along CI and CI $\cdot \Delta \rho_{i j}$ values for all combinations. Note, importantly, that if a critical activity has multiple predecessors (e.g. activity 5 in Figure $4 \mathrm{~b}$ ), its $\mathrm{CI}=1$ must be split into fractional $\mathrm{CI}$ cases for $\mathrm{CI}$ of each predecessor (e.g. split $\mathrm{CI}=1$ of activity 5 into 0.83 and 0.17 for its predecessors). The sum of $\mathrm{CI} \cdot \Delta \rho_{i j}$ for all activities will always equal 1 in all schedules, which verifies Equation 8 . Observations are as follows:

1. An activity with a large $\mathrm{CI} \cdot \Delta \rho_{i j}$ is defined as being crucial, which means that the contribution of this activity to the total project performance is rather large. Note the criteria for cruciality can be set subjectively. For example, per Figure 4 and Table 3, $\geqslant 0.1$ in schedule \#2, $\geqslant 0.3$ in schedule \#3, and $\geqslant 0.1$ in schedule \#4, respectively .

2. An activity contributes the value $\mathrm{CI} \cdot \Delta \rho_{i j}$ to a project delay of 1 day, e.g. 0.117 days for activity 2 in schedule \#2;

3. The sum of $\mathrm{CI} \cdot \Delta \rho_{i j}$ values of activities within the same path is the potential contribution of said path toward an assumed project delay of 1 day, e.g. $0.06375+0.04794=0.11169$ days for activities 2 and 4 in schedule \#4;

4. A negative $\mathrm{CI} \cdot \Delta \rho_{i j}$ value usually occurs in the less critical path (with small $\mathrm{CI} \neq 0$ ), e.g. -0.187 days for activity 3 in schedule \#3. This phenomenon stems from the negative $\rho_{i j}$ of the less critical activity, because its EF typically does not have the same trend as the EF of its critical predecessor. It therefore acts desirably against a project delay of 1 day, in that a negative contribution is its buffering capacity that can locally absorb such delays. Local delays have a cumulative, structure-dependent, quantifiable impact as ripple effects on project performance. Having explored these network behaviors with experiments on the example schedules fulfills Research Objective 2.

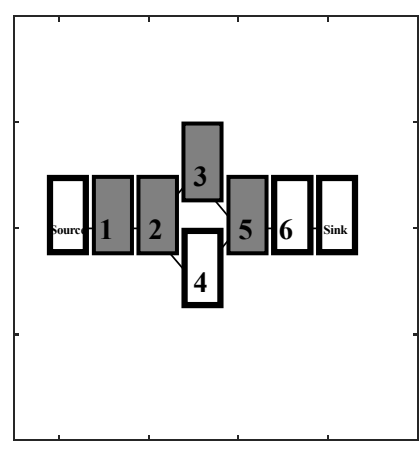

(a) Schedule \#2

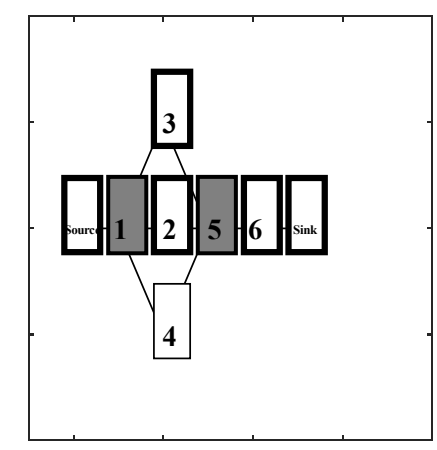

(b) Schedule \#3

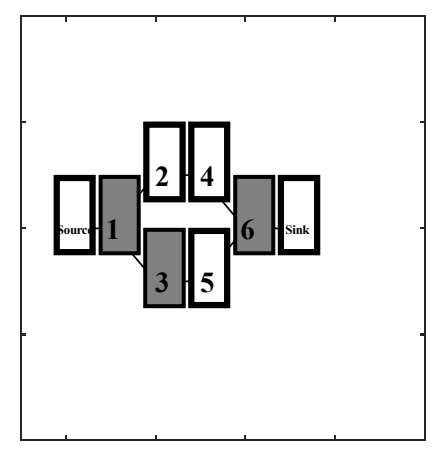

(c) Schedule \#4

Figure. 4. Network Graphs of Schedules \#2, \#3, and \#4 
Table 3. Results Summary for Schedules \#2, \#3, and \#4

\begin{tabular}{|c|c|c|c|c|c|c|c|c|c|}
\hline \multirow{2}{*}{$\begin{array}{l}\text { Schedule } \\
\text { Activity }\end{array}$} & \multicolumn{3}{|c|}{$\# 2$} & \multicolumn{3}{|c|}{$\# 3$} & \multicolumn{3}{|c|}{$\# 4$} \\
\hline & $\mathrm{CI}$ & $\Delta \rho_{i j}$ & $\mathrm{CI} \cdot \Delta \rho_{i j}$ & $\mathrm{CI}$ & $\Delta \rho_{i j}$ & $\mathrm{CI} \cdot \Delta \rho_{i j}$ & CI & $\Delta \rho_{i j}$ & $\mathrm{CI} \cdot \Delta \rho_{i j}$ \\
\hline 1 & 1 & 0.280 & 0.280 & 1 & 0.475 & 0.475 & 1 & 0.225 & 0.225 \\
\hline 2 & 1 & 0.117 & 0.117 & 0.85 & 0.022 & 0.0187 & 0.51 & 0.125 & 0.06375 \\
\hline 3 & 0.83 & 0.290 & 0.2407 & 0.15 & $\underline{-0.187}$ & $\underline{-0.02805}$ & 0.49 & 0.335 & 0.16415 \\
\hline 4 & 0.17 & 0.031 & 0.00527 & 0 & $\underline{-0.144}$ & 0 & 0.51 & 0.094 & 0.04794 \\
\hline \multirow[t]{4}{*}{5} & $1=$ & & & $1=$ & & & 0.49 & 0.058 & 0.02842 \\
\hline & 0.83 & 0.248 & 0.20584 & 0.85 & 0.412 & 0.3502 & & & \\
\hline & 0.17 & 0.507 & 0.08619 & 0.15 & 0.621 & 0.09315 & & & \\
\hline & & & & 0 & 0.578 & 0 & & & \\
\hline \multirow[t]{3}{*}{6} & 1 & 0.065 & 0.065 & 1 & 0.091 & 0.091 & $1=$ & & \\
\hline & & & & & & & 0.51 & 0.556 & 0.28356 \\
\hline & & & & & & & 0.49 & 0.382 & 0.18718 \\
\hline Sum & N/A & N/A & 1.0000 & N/A & N/A & 1.0000 & N/A & N/A & 1.0000 \\
\hline
\end{tabular}

\section{Validation}

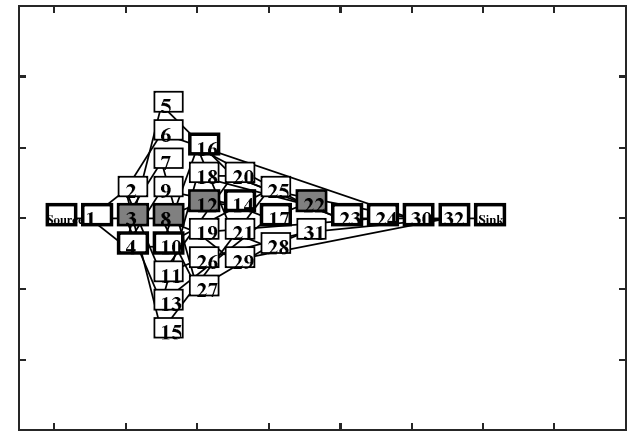

Figure. 5. Network Graph for Schedule J30
A benchmark schedule (J30) from the Project Scheduling Problem Library (PSPLIB) [51] is used to assess the robustness of Equation 8 in a larger, more complex network. Figures 5 shows it with crucial activities in gray. Per Table 4 , the sum of CI $\cdot \Delta \rho_{i j}$ for all activities is 1.0000. All three observations still exist in this complex schedule.

If a critical activity has multiple predecessors (e.g. 22 in Table 4), then its CI is split into fractions 0.78 and 0.22 to consider the CI of its predecessors 16 and 17. Practical suggestions can be derived:

\section{Delay avoidance:}

1. Focus on those activities with larger CI $\cdot \Delta \rho_{i j}$, because they potentially contribute more toward a project delay;

2. Focus on paths with larger CI $\cdot \Delta \rho_{i j}$, because they carry a higher risk of propagating delays and are 'crucial';

3. In the order of importance, focus first on managing the larger $\mathrm{CI} \cdot \Delta \rho_{i j}>$ smaller CI $\cdot \Delta \rho_{i j}>$ negative CI $\cdot \Delta \rho_{i j}$;

4. Create less sequential paths in a schedule, which can protect the project duration. The CI $\cdot \Delta \rho_{i j}$ provide a good indicator to select which path should be rescheduled toward being more concurrent. In sequence of increasing utility, this means larger $\mathrm{CI} \cdot \Delta \rho_{i j}$ (more sequential) $>$ smaller $\mathrm{CI} \cdot \Delta \rho_{i j}>$ negative $\mathrm{CI} \cdot \Delta \rho_{i j}$ (more concurrent).

Table 4. Result Summary for Schedule J30

\begin{tabular}{|c|c|c|c|c|c|c|c|c|c|c|c|c|c|c|c|}
\hline Activity & $\mathrm{CI}$ & $\Delta \rho_{i j}$ & $\mathrm{CI} \cdot \Delta \rho_{i j}$ & Activity & CI & $\Delta \rho_{i j}$ & $\mathrm{CI} \cdot \Delta \rho_{i j}$ & Activity & $\mathrm{CI}$ & $\Delta \rho_{i j}$ & $\mathrm{CI} \cdot \Delta \rho_{i j}$ & Activity & $\mathrm{CI}$ & $\Delta \rho_{i j}$ & $\mathrm{CI} \cdot \Delta \rho_{i j}$ \\
\hline 1 & 1 & 0 & 0 & 8 & 0.78 & 0.163 & 0.12714 & 17 & 0.78 & 0.019 & 0.01482 & 24 & 1 & 0.036 & 0.036 \\
\hline 2 & 0 & 0.144 & 0 & 9 & 0 & $*$ & 0 & 18 & 0 & $*$ & 0 & 25 & 0 & $*$ & 0 \\
\hline 3 & 0.78 & 0.431 & 0.33618 & 10 & 0.22 & 0.054 & 0.01188 & 19 & 0 & $*$ & 0 & 26 & 0 & $*$ & 0 \\
\hline 4 & 0.22 & 0.008 & 0.00176 & 11 & 0 & $*$ & 0 & 20 & 0 & $*$ & 0 & 27 & 0 & $*$ & 0 \\
\hline 5 & 0 & $*$ & 0 & 12 & 0.78 & 0.138 & 0.10764 & 21 & 0 & * & 0 & 28 & 0 & $*$ & 0 \\
\hline \multirow[t]{3}{*}{6} & 0 & $*$ & 0 & 13 & 0 & $*$ & 0 & 22 & $1=$ & & & 29 & 0 & $*$ & 0 \\
\hline & & & & 14 & 0.78 & 0.021 & 0.01638 & & 0.78 & 0.895 & 0.1969 & 30 & 1 & 0.015 & 0.015 \\
\hline & & & & 15 & 0 & $*$ & 0 & & 0.22 & 0.162 & 0.12636 & 31 & 0 & $*$ & 0 \\
\hline \multirow[t]{2}{*}{7} & 0 & $*$ & 0 & 16 & 0.22 & $\underline{\underline{-0.023}}$ & $\underline{-0.00506}$ & 23 & 1 & 0.015 & 0.015 & 32 & 1 & 0 & 0 \\
\hline & & & & & & & & & & & & Sum & N/A & N/A & 1.0000 \\
\hline
\end{tabular}

\section{Delay analysis:}

1. It is possible to measure the magnitude of the contribution of each activity toward a project delay of 1 day; 
2. Critical activities at a merge merit special attention. Although its CI is 1 , it could be split into fractional CIs. This has potential to be applied for assigning delay responsibility to concurrent activities in shares of $\mathrm{CI} \cdot \Delta \rho_{i j}$;

3. Activities with negative CI $\cdot \Delta \rho_{i j}$ arise because of a negative $\rho_{i j}$ for the less critical activity. This phenomenon occurs, because most of the time the less critical activity is noncritical (does not affect the project finish).

Having summarized practical suggestions for delay avoidance and delay analysis fulfills Research Objective 3.

\section{Conclusions}

Construction schedules have lacked local performance indices to measure the potential contributions of individual activities to the total project finish. The product of the elements of correlation coefficient and reachability matrices has filled this gap. But a schedule has its unique network structure that determines not just criticality, but also the new cruciality. Therefore this paper has developed a new methodology for performance measurement that considers the network structure and correlation coefficient between two reachable activities' finish time within a schedule. Cumulative and noncumulative forms of product matrices have been plotted in 3D profiles. The former lists the ripple effect in its last column; the latter lists the noncumulative correlation coefficient values multiplied by their corresponding criticality index to gain their cruciality $\mathrm{CI} \cdot \Delta \rho_{i j}$ and must sum to one. Activities with nonzero CI are critical, but not all of them are crucial (with larger CI $\cdot \Delta \rho_{i j}$ ). Crucial means the contribution of an individual activity to the total project performance is relatively large. The meaning of individual CI $\cdot \Delta \rho_{i j}$ values within a schedule has been studied by testing several examples. Applying it to a more complex schedule from PSPLIB, the robustness of the results has been validated. Practical suggestions for delay avoidance and delay analysis have been derived from these observations and explained. They include focusing on more crucial activities and the paths that contain them, and potentially reworking the structure toward a more concurrent one that may help avoid or reduce delay impacts.

\section{Acknowledgements}

The support of the National Science Foundation (Grant CMMI-1536005) and Charles Pankow Foundation (Pankow \#07-16) for portions of the work presented here is gratefully acknowledged. Any opinions, findings, and conclusions or recommendations expressed in this material are those of the author and do not necessarily represent the views of the National Science Foundation and Charles Pankow Foundation.

\section{References}

[1] Kerzner, H. (2013). Project Management: A Systems Approach to Planning, Scheduling, and Controlling. 11 ${ }^{\text {th }}$ ed., Wiley, Hoboken, NJ.

[2] Mincks, W. R., Johnston, H. (2004). Construction Jobsite Management. $2^{\text {nd }}$ ed., Thomson/Delmar Learning, Clifton Park, NY.

[3] Wanberg, J., Harper, C., Hallowell, M. R., Rajendran, S. (2013). "Relationship between Construction Safety and Quality Performance." Journal of Construction Engineering and Management, 139(10): 04013003(10).

[4] Hallowell, M. R. (2012). "Safety-Knowledge Management in American Construction Organizations." J. Mgmt. Eng., 28(2): $203-211$.

[5] Borges, W. F., Mário, P. do C. (2017). "Five Project-Duration Control Methods in Time Units: Case Study of a Linearly Distributed Planned Value." Journal of Construction Engineering and Management, 05017002(14).

[6] Creese, R. C., Fang, Y. (2010). “Time-Based Schedule Performance Index.” Cost Engineering, 52(3): 18-20.

[7] Lipke, W. H. (2003). "Schedule is Different." The Measurable News: Quarterly Magazine of the Project Management Institute College of Performance Measurement, March 2003, <http://www.earnedschedule.com/docs/schedule\%20is\%20different.pdf>, Schedule Division, Oklahoma City Air Logistics Center, Tinker Air Force Base, Oklahoma City, OK, accessed November 9, 2017: 10 pp.

[8] Lipke, W. H. (2012). "Speculations on Project Duration Forecasting." PM World Today, 14(3): 11 pp.

[9] Thompson, R. C., Su, Y., Lucko, G. (2017). "Measuring Project Performance Inspired by Stock Index.” Procedia Engineering, 196: $706-713$.

[10] Al-Momani, A. H. (2000). "Construction delay: a quantitative analysis." International Journal of Project Management, 18(1): 51-59.

[11] González, P., González, V., Molenaar, K. A., Orozco, F. (2013). "Analysis of Causes of Delay and Time Performance in Construction Projects.” Journal of Construction Engineeringand Management, 140(1): 04013027(9).

[12] Acharya, N. K., Lee, Y. D., Kim, S. Y., Lee, J. C., Kim, C. S. (2006). "Analysis of Construction Delay Factor: A Korean Perspective.” Proceedings of the $7^{\text {th }}$ Asia Pacific Industrial Engineering and Management Systems Conference, ed. Kachitvichyanuku, V., Bangkok, Thailand, December 17-20, 2006, Asian Institute of Technology, Pathumthani, Thailand: 883-895.

[13] AlSehaimi, A., Koskela, L., Tzortzopoulos, P. (2013). "Need for Alternative Research Approaches in Construction Management: Case of Delay Studies." Journal of Management in Engineering, 29(4): 407-413.

[14] Larsen, J. K., Shen, G. Q., Lindhard, S. M., Brunoe, T. D. (2016). "Factors Affecting Schedule Delay, Cost Overrun, and Quality Level in Public Construction Projects." Journal of Management in Engineering, 32(1): 04015032(10).

[15] Cooke-Davies, T. (2002). "The "real" success factors on projects." International Journal of Project Management, 20(3): 185-190.

[16] Hwang, B.-G., Lim, E.-S., J. (2013). “Critical Success Factors for Key Project Players and Objectives: Case Study of Singapore.”Journal of Construction Engineering and Management, 139(2): 204-215. 
[17] Ellis, R. D., Thomas, H. R. (2003). "The root causes of delays in highway construction.” Proceedings of the $82^{\text {nd }}$ Annual Meeting, Washington, DC, January 11-16, 2003, Transportation Research Board, Washington, DC: 16 pp.

[18] Koushki, P. A., Al-Rashid, K., Kartam, N. (2005). "Delays and cost increases in the construction of private residential projects in Kuwait." Construction Management and Economics, 23(3): 285-294.

[19] Lopez del Puerto, C., Shane, J. S. (2014). "Keys to Success in Megaproject Management in Mexico and the United States: Case Study." Journal of Construction Engineering and Management, 140(4): B5013001(7).

[20] Lo, T. Y., Fung, I. W. H., Tung, K. C. F. (2006). "Construction Delays in Hong Kong Civil Engineering Projects." Journal of Construction Engineering and Management, 132(6): 636-649.

[21] Ruqaishi, M., Bashir, H. A. (2015). "Causes of Delay in Construction Projects in the Oil and Gas Industry in the Gulf Cooperation Council Countries: A Case Study.” Journal of Management in Engineering, 31(3): 05014017(8).

[22] Kadry, M., Osman, H., Georgy, M. (2016). "Causes of Construction Delays in Countries with High Geopolitical Risks." Journal of Construction Engineering and Management, 143(2): 04016095(11).

[23] Arditi, D., Pattanakitchamroon, T. (2008). "Selecting a delay analysis method in resolving construction claims." International Journal of Project Management, 24(2): 145-155.

[24] Braimah, N., Ndekugri, I. (2008). "Factors influencing the selection of delay analysis methodologies." Int. J. Proj. Mgmt., 26(8): 789-799.

[25] Mehany, M. S. H. M. (2014). Delay-caused claims in infrastructure projects under design-bid-build delivery systems. Dissertation, Colorado State University, Fort Collins, CO: 306 pp.

[26] Perera, N. A., Sutrisna, M., Yiu, T. W. (2016). "Decision-Making Model for Selecting the Optimum Method of Delay Analysis in Construction Projects.” Journal of Management in Engineering, 32(5): 04016009(14).

[27] Mohan, S. B., Al-Gahtani, K. S. (2006). "Current Delay Analysis Techniques and Improvements.” Cost Engineering, 48(9): 12-21.

[28] Finke, M. R. (1997). "Contemporaneous analyses of excusable delays." Cost Engineering, 39(12): 26-31.

[29] Finke, M. R. (1999). "Window Analyses of Compensable Delays.” Journal of Construction Engineering and Management, 125(2): 96-100.

[30] Valadares Tavares, L., Antunes Ferreira, J., Silva Coelho, J. (1999). "The risk of delay of a project in terms of the morphology of its network." European Journal of Operational Research, 119(2): 510-537.

[31] Nassar, K. M., Hegab, M. Y. (2006). "Developing a Complexity Measure for Project Schedules.” J. Constr. Eng. Mgmt., 132(6): 554-561.

[32] Nassar, K. M. (2010). "Schedule network complexity versus project complexity." Proceedings of the International Conference on Computing in Civil and Building Engineering, ed. Tizani, W., Nottingham, Great Britain, June 30 - July 2, 2010, Nottingham University Press, Great Britain: 9 pp.

[33] Sinha, S., Kumar, B., Thomson, A. (2006). “Measuring Project Complexity: A Project Manager’s Tool.” Arch. Eng. Des. Mgmt.itectural Engineering and Design Management, 2(3): 187-202.

[34] Vidal, L.-A., Marle, F., Bocquet, J.-C. (2007). "Modelling Project Complexity.” Proceedings of the International Conference on Engineering Design, ed. Bocquet, J.-C., Paris, France, August 28-31, 2007, Design Society, Bristol, Great Britain: 10 pp.

[35] Sheard, A. A. (2012). Assessing the impact of complexity attributes on system development project outcomes. Dissertation, Stevens Institute of Technology, Hoboken, NJ: 329 pp.

[36] Latva-Koivisto, A. M. (2001). Finding a complexity measure for business process models. Research Report, $13^{\text {th }}$ February, 2001, Mat-2.108 Individual Research Projects in Applied Mathematics, Systems Analysis Laboratory, Helsinki University of Technology, Finland: 26 pp.

[37] Haponava, T., Al-Jibouri, S. (2012). "Proposed System for Measuring Project Performance Using Process-Based Key Performance Indicators." Journal of Management in Engineering, 28(2): 140-149.

[38] Nassar, N., AbouRizk, S. M. (2014). "Practical Application for Integrated Performance Measurement of Construction Projects." Journal of Management in Engineering, 30(6): 04014027(11).

[39] Esmaeili, B., Franz, B., Molenaar, K. R., Leicht, R. M., Messner, J. I. (2013). “A Review of Critical Success Factors and Performance Metrics on Construction Projects." Proceedings of the $4{ }^{\text {th }}$ Construction Specialty Conference at the CSCE Annual Conference, eds. Attalla, M., Francis, A., Montréal, Québec, Canada, May 29 - June 1, CSCE, Montréal, Québec, Canada: CON-62-1 - CON-62-10.

[40] Sarhan, S., Fox, A. (2013). "Performance Measurement in the UK Construction Industry and its Role in Supporting the Application of Lean Construction Concepts.” Australasian Journal of Construction Economics and Building, 13(1): 23-35

[41] Iyer, K. C, Jha, K. N. (2006). "Critical Factors Affecting Schedule Performance: Evidence from Indian Construction Projects." Journal of Construction Engineering and Management, 132(8): 871-881.

[42] Levinson, M. (2009). The Economist: Guide to financial markets. $5^{\text {th }}$ ed., Wiley, Hoboken, NJ.

[43] Sahoo, P. (2013). Probability and Mathematical Statistics. University of Louisville, Louisville, KY.

[44] Oprea, D. S. (2015). "The Interval Effect in Estimating Beta: Empirical Evidence from the Romanian Stock Market." Review of Finance and Banking, 7(2): 16-25.

[45] Gong, S. X., Firth, M., Cullinane, K. (2006). "Beta estimation and stability in the US-listed international transportation industry." Review of Pacific Basin Financial Markets and Policies, 9(3): 463-490.

[46] Thompson, R. C., Lucko, G. (2013). "Modeling Measures of Risk Correlation for Quantitative Float Management of Construction Projects." Proceedings of the $5^{\text {th }}$ International Conference on Construction Engineering and Project Management, ed. Kim, H., Anaheim, California, January 9-11, 2013, University of North Carolina, Charlotte, NC: 8 pp.

[47] Lucko, G., Su, Y. (2017). "Precedence Pattern Permutations Creating Criticality Constellations: Exploring a Conjecture on Non-linear Activities with Continuous Links. Procedia Engineering, 196: 714-722.

[48] Kenny, D. A. (1979). Correlation and Causality. Wiley, New York City, NY.

[49] Schwindt, C. (1995). ProGen/max: A new problem generator for different resource-constrained project scheduling problems with minimal and maximal time lags. Report WIOR-449, Institut für Wirtschaftstheorie und Operations Research, Universität Karlsruhe, Germany: 57 pp.

[50] Su, Y., Lucko, G., Thompson, R. C. (2016). "Evaluating Performance of Critical Chain Project Management to Mitigate Delays Based on Different Schedule Network Complexities." Proceedings of the $48^{\text {th }}$ Winter Simulation Conference, eds. Roader, T. M. K., Frazier, P. I., Szechtman, R., Zhou, E., Huschka, T., Chick, S. E., Washington, DC, December 11-14, 2016, IEEE, Piscataway, NJ: 3314-3324.

[51] Kolisch, R., Sprecher, A. (1996). "PSPLIB - A Project Scheduling Library.” European Journal of Operational Research, 96(1): 205-216. 